\title{
Circular RNA derived from TIMP2 functions as a competitive endogenous RNA and regulates intervertebral disc degeneration by targeting miR-185-5p and matrix metalloproteinase 2
}

\author{
WEI GUO ${ }^{1}$, BIN ZHANG $^{2}$, CHAO SUN $^{2}$, HUI-QUAN DUAN ${ }^{2}$, WEI-XIAO LIU ${ }^{2}$, KUN MU $^{3}$, \\ LING ZHAO $^{1}$, HAO-RAN LI ${ }^{1}$, ZHAN-YIN DONG ${ }^{1}$ and QING CUI ${ }^{1}$ \\ ${ }^{1}$ Department of Orthopaedics, Hebei Province Cangzhou Hospital of Integrated Traditional and \\ Western Medicine (Cangzhou No. 2 Hospital), Cangzhou, Hebei 061001; ${ }^{2}$ Department of Orthopaedics, \\ Tianjin Medical University General Hospital, Tianjin 300052; ${ }^{3}$ Department of Breast Surgery, Hebei Province Cangzhou \\ Hospital of Integrated Traditional and Western Medicine (Cangzhou No. 2 Hospital), Cangzhou, Hebei 061001, P.R. China
}

Received September 28, 2019; Accepted May 4, 2020

DOI: $10.3892 /$ ijmm.2020.4621

\begin{abstract}
Intervertebral disc degeneration (IDD) is an important cause of lower back pain, although the underlying mechanisms remain poorly understood. The present study aimed to examine the role of a circular RNA derived from tissue inhibitor of metallopeptidases 2 (circ-TIMP2) in degenerative nucleus pulposus (NP) tissues, and to validate its function in cultured human NP cells. Overexpression of miR-185-5p in NP cells markedly inhibited the enhanced extracellular matrix (ECM) catabolism induced by tumor necrosis factor- $\alpha$ (TNF- $\alpha$ ) and interleukin-1 $\beta$ (IL-1 $\beta$ ) treatment. Bioinformatics analysis demonstrated that matrix metalloproteinase 2 (MMP2) was a potential target of miR-185-5p. MMP2 protein expression levels were increased following treatment with TNF- $\alpha$ and IL-1 $\beta$ in NP cells compared with those in untreated cells, and this effect was attenuated by transfection with miR-185-5p. Compared with normal NP tissues, IDD samples exhibited higher circ-TIMP2 expression levels. In addition, overexpression of circ-TIMP2 promoted ECM catabolism and suppressed ECM anabolism. Furthermore, circ-TIMP2 sequestered miR-185-5p, which may potentially upregulate the target genes associated with ECM degradation. In conclusion, the results of the present study revealed that circ-TIMP2 promoted TNF- $\alpha$ - and IL- $1 \beta$-induced NP cell imbalance between ECM anabolism and catabolism via miR-185-5p-MMP2 signaling. These findings provide a potential therapeutic option for the treatment of IDD.
\end{abstract}

Correspondence to: Dr Wei Guo, Department of Orthopaedics, Hebei Province Cangzhou Hospital of Integrated Traditional and Western Medicine (Cangzhou No. 2 Hospital), 31 Huanghe Road, Cangzhou, Hebei 061001, P.R. China

E-mail: guow0319@163.com

Key words: intervertebral disk degeneration, circ-TIMP2, miR-185-5p, matrix metalloproteinase 2, nucleus pulposus

\section{Introduction}

Intervertebral disc degeneration (IDD) is a common degenerative disease, as a total of 266 million individuals worldwide have degenerative spine disease annually (1). IDD features include accelerated extracellular matrix (ECM) degradation and abnormal ECM biosynthesis, decreased hydration, reduced intervertebral disc height and decreased ability to absorb external mechanical compression $(2,3)$. IDD is the predominant cause of chronic lower back pain and spine-related ailments, imposing significant economic and social burden worldwide (4). According to previous reports, $84 \%$ of the world population experiences lower back pain during their lifetime, with $10 \%$ being chronically disabled (5). However, the application of current strategies for IDD treatment is hampered by an incomplete understanding of its pathogenesis. IDD treatment is limited to symptomatic interventions, which do not adequately improve outcomes since no disease-modifying drugs are available (6). Consequently, the clinical management of diseases related to IDD remains severely limited. Therefore, determining the pathophysiological events and molecular mechanisms underlying IDD is urgently needed for the development of new treatments.

Intervertebral discs are composed of a central nucleus pulposus (NP), a peripheral annulus fibrosus (AF) and cartilaginous end plates, which connect overlying capillary beds cranially and caudally (7). NP cells are the predominant cell type in the NP tissue, which forms the main component of the ECM by synthesizing type II collagen (collagen II) and aggrecan, the major functional components of intervertebral discs, to maintain normal disc height and to absorb various mechanical loads (7). Multiple adverse factors such as Substance $\mathrm{P}$, chemokine ligand 5 and chronic overload of the disc (8-10) enhance the levels of inflammatory cytokines (ICs) in the NP, including interleukin-1 $\beta$ (IL-1 $\beta$ ) and tumor necrosis factor- $\alpha$ (TNF- $\alpha)(11,12)$. IL-1 $\beta$ contributes to IDD development by accelerating the degradation of ECM components, e.g., via increased production of catabolic factors such as matrix metalloproteinases (MMPs) $(11,12)$. TNF- $\alpha$ influences 
catabolic pathways in a manner similar to IL-1 $\beta$; TNF- $\alpha$ and IL-1 $\beta$ have been demonstrated to induce degenerative changes to the ECM, which is a major characteristic of disc degeneration (13). These ICs have been demonstrated to induce an imbalance between anabolic and catabolic activities in NP cells and to inhibit the expression of anabolic factors such as collagen II and aggrecan, which initiate or accelerate the development of IDD $(8,11,13,14)$. Thus, it is necessary to develop an effective tool to attenuate the inflammatory response and to reverse the imbalance between anabolism and catabolism within the NP microenvironment.

Multiple molecular inducers of IDD have been reported in previous studies, with non-coding RNAs emerging as key factors affecting IDD pathogenesis $(15,16)$. Circular RNAs (circRNAs) are a class of RNAs with circular structures without 5'-3' polarity and polyadenylation tails, and are mostly produced by one or more exons through reverse splicing (17). Most circRNAs are endogenous non-coding RNAs conserved across species and exhibit higher stability compared with linear mRNAs (18). Competing endogenous RNAs (ceRNAs) induce mRNA silencing by binding to the 3'-untranslated region response element, also termed the microRNA (miRNA) response element $(17,19)$. circRNAs can also bind miRNAs to participate in the regulatory network of ceRNAs (19). Thus, circRNAs act as post-transcriptional regulators and interact with miRNAs as miRNA sponges and ceRNAs in the cytoplasm (21-23). miRNA sponges are circRNAs with miRNA binding capacity that absorb miRNAs and inhibit their repressive effects on respective targets (24). A previous study has revealed that miR-185-5p is downregulated in degenerative NP tissues (15). In addition, bioinformatics analysis has demonstrated the ability of miR-185-5p to interact with several circRNAs (15). However, the mechanisms by which miR-185-5p affects IDD development and progression remain unclear.

Our previous study demonstrated that circGRB10 promoted the survival of NP cells during nutrient deprivation by upregulating Erb-B2 receptor tyrosine kinase through the inactivation of miR-328-5p, which suppressed IDD development (25). Therefore, it was hypothesized in the present study that circ-RNAs may be involved in the pathogenesis of IDD through by regulating miR-185-5p. The present study aimed to examine the role of circ-RNAs in degenerative NP tissues and to validate their functions in cultured human NP cells.

\section{Materials and methods}

Ethics statement. This study was approved by the ethics committees of Tianjin Medical University General Hospital (Tianjin, China) and Hebei Province Cangzhou Hospital of Integrated Traditional and Western Medicine (Cangzhou, China). Human NP tissue samples were obtained from patients undergoing surgery between January 2018 and May 2019 at Tianjin Medical University General Hospital and Hebei Province Cangzhou Hospital of Integrated Traditional and Western Medicine. Written informed consent was obtained from all patients for the use of their tissue specimens for research purposes.

Clinical specimens. Human lumbar degenerative NP specimens were obtained from 10 patients with IDD undergoing discectomy. Control samples were obtained from 10 age- and sex-matched patients with fresh traumatic lumbar fracture undergoing anterior decompressive surgery due to neurological deficits. The characteristics of the patients are presented in Table I. The degree of IDD was determined by magnetic resonance imaging and graded using the following grading system for the assessment of lumbar disc degeneration: i) Grade I, homogeneous disc structure with a bright hyperintense white signal and a normal disc height; ii) grade II, inhomogeneous disc structure with a hyperintense white signal, clear distinction between the nucleus and annulus, and normal disc height, with or without horizontal gray bands; iii) grade III, inhomogeneous disc structure with an intermediate gray signal intensity, unclear distinction between the nucleus and annulus, and normal or slightly decreased disc height; iv) grade IV, inhomogeneous disc structure with a hypointense dark gray signal intensity, no distinction between the nucleus and annulus, and normal or moderately decreased disc height; v) grade V, inhomogeneous disc structure with a hypointense black signal intensity, no distinction between the nucleus and annulus, and collapsed disc space. Grading was performed using T2-weighted midsagittal fast spin echo images (repetition time, 5,000 ms; echo time, $130 \mathrm{~ms}$ ) (26-28). The lesions in the control group were of grade I or II, whereas those in patients with IDD were of grade III, IV or V.

Isolation and culture of human NP cells. The NP was separated from $\mathrm{AF}$ samples under a stereotactic microscope and sliced at 2-3 $\mathrm{mm}^{3}$ as previously described (20). NP cells were obtained after digestion with $0.25 \mathrm{mg} / \mathrm{ml}$ type II collagenase (Invitrogen; Thermo Fisher Scientific, Inc.) for $12 \mathrm{~h}$ at $37^{\circ} \mathrm{C}$ in Dulbecco's modified Eagle's medium/nutrient mixture F-12 (DMEM/F12; Gibco; Thermo Fisher Scientific, Inc.) and resuspended at $2 \times 10^{5}$ cells/ml in DMEM/F12 supplemented with $10 \%$ fetal bovine serum (Gibco; Thermo Fisher Scientific, Inc.), $100 \mathrm{mg} / \mathrm{ml}$ streptomycin, $100 \mathrm{U} / \mathrm{ml}$ penicillin and $1 \%$ L-glutamine at $37^{\circ} \mathrm{C}$ in a humidified atmosphere containing $5 \%$ $\mathrm{CO}_{2}$. At confluency, the cells were trypsinized and passaged, with the medium changed every other day. Cells at the second passage were assessed in the experiments. In the IC treatment experiments, cells were stimulated by $5 \mathrm{ng} / \mathrm{ml}$ of TNF- $\alpha$ and IL-1 $\beta$ (Sigma-Aldrich; Merck KGaA) in the culture medium for $12 \mathrm{~h}$. Unstimulated cells were used as controls.

Bioinformatics analysis. Using the starBase platform (http://starbase.sysu.edu.cn), miR-185-5p was predicted to have binding sites for a circRNA derived from tissue inhibitor of metalloproteinases 2 (circ-TIMP2).

Small interfering RNA(siRNA) and circ-TIMP2 overexpression plasmid construction. According to the circRNA sequences of circ-TIMP2 (hsa_circ_0045942) in circBase (http://www. circbase.org/), circ-TIMP2 siRNA (each siRNA had three pairs of sequences) and negative control (NC) siRNA were designed and synthesized by Guangzhou Geenseed Biotech Co., Ltd. To construct a circ-TIMP2 overexpression vector, front and back circular frames of TIMP2 were generated and added to a pLCDH-ciR vector (Geneseed Biotech Co., Ltd.) for transcript circularization. The front and back circular frames comprised endogenous flanking genomic sequences 
Table I. Clinicopathological features of the study population.

\begin{tabular}{lccc}
\hline Variable & $\begin{array}{c}\text { Normal } \\
(\mathrm{n}=10)\end{array}$ & $\begin{array}{c}\text { IDD } \\
(\mathrm{n}=10)\end{array}$ & P-value \\
\hline Age, years & $36.2 \pm 10.4$ & $34.6 \pm 10.3$ & $0.733^{\mathrm{a}}$ \\
Body mass index, $\mathrm{kg} / \mathrm{m}^{2}$ & $23.9 \pm 2.2$ & $24.0 \pm 2.2$ & $0.982^{\mathrm{a}}$ \\
$\begin{array}{l}\text { Sex, } \mathrm{n}(\%) \\
\text { Male }\end{array}$ & $7(70)$ & $5(50)$ & $0.650^{\mathrm{b}}$ \\
Female & $3(30)$ & $5(50)$ & \\
\hline
\end{tabular}

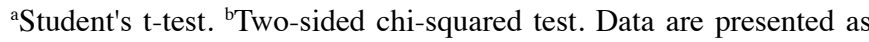
the mean \pm SD or count $(\%)$.

with EcoRI and BamHI restriction sites, respectively (24). The 3,122 bp target sequence comprised the EcoRI site, the splice acceptor AG, the circ-TIMP2 sequence, the splice donor GT, and the BamHI site. The PCR product was cloned between the two frames. The specific divergent primers for the back-splice junction of circ-TIMP2 were used to amplify the circRNA. A mock vector solely containing a nonsense sequence between both circular frames without circ-TIMP2 cDNA was generated. Vector construction was performed by Guangzhou Geenseed Biotech Co. miR-185-5p and MMP2 siRNAs, as well as the corresponding negative controls, were synthesized from Guangzhou RiboBio Co., Ltd.

Cell transfection. NP cells of the second generation underwent transfection with respective plasmids or siRNAs using Lipofectamine ${ }^{\circledR} 3000$ (Invitrogen) according to the manufacturer's instructions. NP cells at $80 \%$ confluence were transfected with the siRNAs using Lipofectamine ${ }^{\circledR} 3000$ (Invitrogen; Thermo Fisher Scientific, Inc.) at $37^{\circ} \mathrm{C}$ for $6 \mathrm{~h}$, and subsequently the media was replaced. The siRNA concentration for each transfection was $135 \mathrm{ng} / \mu 1$, and the plasmid concentration was $100 \mathrm{ng} / \mathrm{ml}$. The cells were harvested at $48 \mathrm{~h}$ post-transfection. The transfection efficiency was determined by Reverse transcription-quantitative (RT-q) PCR.

$R T-q P C R$. Total RNAs were extracted using the miRNeasy Mini kit (Qiagen $\mathrm{GmbH}$ ) on isolated NP cells. For circRNA, total RNAs were incubated with or without $3 \mathrm{U} / \mu \mathrm{g}$ of RNase $\mathrm{R}$ (Epicentre; Illumina, Inc.) at $37^{\circ} \mathrm{C}$ for $20 \mathrm{~min}$, and the resulting RNA was subsequently purified using the RNeasy MinElute Cleanup kit (Qiagen $\mathrm{GmbH}$ ). circ-TIMP2 levels were assessed by SYBR ${ }^{\circledast}$ Green-based qPCR (Sigma-Aldrich; Merck KGaA). miRNA levels were determined using stem-loop miRNA RT-PCR Quantitation kit (Shanghai GenePharma Co., Ltd.). RNA was reverse-transcribed using a PrimeScipt RT kit (Takara Bio, Inc.) at $37^{\circ} \mathrm{C}$ for 15 min followed by inactivation of reverse transcriptase with heat treatment at $85^{\circ} \mathrm{C}$ for $5 \mathrm{sec}$. cDNA was used to perform qRT-PCR on the 7500 Sequence Detection System (Applied Biosystems; Thermo Fisher Scientific, Inc.) using SYBR ${ }^{\circledR}$ Premix Ex Taq (Takara Bio, Inc.). All primers used in the present study are listed in Table II. Adaptor primers were designed for the reverse splice site of circTIMP2. PCR amplification was performed in 10- $\mu 1$ reaction mixtures comprising $2 \mu \mathrm{l} \mathrm{cDNA}, 5 \mu \mathrm{l} 2 \mathrm{X}$ master mix,
$0.5 \mu \mathrm{l}$ forward and reverse primers $(10 \mu \mathrm{M})$ and $2 \mu \mathrm{l}$ water at $95^{\circ} \mathrm{C}$ for $10 \mathrm{~min}$, followed by 40 cycles of $95^{\circ} \mathrm{C}$ for $10 \mathrm{sec}$ and $60^{\circ} \mathrm{C}$ for $60 \mathrm{sec}$. GAPDH was used for normalization, with the exception of miRNAs, for which U6 was used. The relative expression levels of each circRNA, mRNA or miRNA were determined by the $2^{-\Delta \Delta \mathrm{Cq}}$ method (29).

Fluorescence in situ hybridization (FISH). FISH was performed to detect the subcellular localization of circ-TIMP2 and miR-185-5p in NP cells according to a method described by Vautrot et al (30). A FISH probe labeled with Alexa Fluor ${ }^{\circledR}$ 488 for circ-TIMP2 (Thermo Fisher Scientific, Inc.) was designed to detect the splice junction of two exons. After prehybridization using $1 \mathrm{X}$ PBS and $0.5 \%$ Triton X-100, NPCs were hybridized in hybridization buffer (50\% formamide, 5X SSC, $500 \mu \mathrm{g} / \mathrm{ml}$ yeast tRNA, 10\% Dextran sulfate, 1X Denhardt's solution, $10 \mathrm{mM}$ DDT, $1 \mathrm{mg} / \mathrm{ml}$ sheared salmon sperm DNA) with specific probes at $55^{\circ} \mathrm{C}$ for $15-17 \mathrm{~h}$ in a humidified chamber. The probe sequence of circ-TIMP2 was 5'-GAT TCTCCTTATCATTACCGAGAAAGTTCTTC-3'. The probe for miR-185-5p was labeled with $\mathrm{Cy} 3$, and the sequence was 5'-TCAGGAACTGCCTTTCTCTCCA-3' (Wuhan Servicebio Technology Co., Ltd.). Images were acquired using an Nikon Eclipse TI-SR fluorescence microscope (Nikon Corporation).

Dual-luciferase reporter assay. The binding site of circ-TIMP2 (31) (wild-type or mutated) was inserted into the $K p n I$ and SacI sites of the pGL3 promoter vector (Shanghai Realgene Biotech, Inc.). First, cells were seeded into 24-well plates $\left(2 \times 10^{5}\right.$ cells/well), followed by transfection with $80 \mathrm{ng}$ plasmid, $5 \mathrm{ng}$ Renilla luciferase vector pRL-SV40 and $50 \mathrm{nM}$ miR-185-5p mimics or respective NCs using $1.5 \mu 1 /$ well Lipofectamine ${ }^{\circledR} 3000$ by incubation for $10-15 \mathrm{~min}$ at room temperature. Cell collection was performed after $48 \mathrm{~h}$, and the Dual-Luciferase Reporter Assay system (Promega Corporation) was used to measure luciferase activity according to the manufacturer's instructions. Firefly luciferase activity was normalized to that of Renilla luciferase.

Western blotting. Western blotting was performed as previously described (25). Cell lysis was performed in a buffer containing $0.25 \mathrm{M}$ Tris- $\mathrm{HCl}, 20 \%$ glycerol, $4 \%$ sodium dodecyl sulfate (SDS) and 10\% mercaptoethanol (pH 6.8) supplemented with protease and phosphatase inhibitors. The protein contents were measured using the Micro BCA Protein Assay kit (Thermo Fisher Scientific, Inc.). Equal amounts of total protein $(10 \mu \mathrm{g})$ were separated on $10-12 \%$ SDS-polyacrylamide gels and electro-transferred onto polyvinylidene fluoride membranes. After blocking with 5\% non-fat milk in Tris-buffered saline with $0.1 \%$ Tween-20 (TBST) at room temperature for $1 \mathrm{~h}$, the membranes were incubated with primary antibodies (1:3,000; collagen-II, cat. no. ab34712, Abcam; aggrecan, cat. no. ab194594, Abcam; MMP-2, cat. no. ab97779, Abcam; GAPDH, cat. no. ab9485, Abcam) in TBST containing 5\% non-fat milk overnight at $4^{\circ} \mathrm{C}$. Secondary horseradish peroxidase-conjugated antibodies (1:6,000; Goat Anti-Rabbit IgG H\&L, cat. no. ab6721; Goat Anti-Mouse IgG H\&L, cat. no. ab205719, Abcam) were added at room temperature for $1 \mathrm{~h}$, and immunoblots were developed using an enhanced chemiluminescence system 
Table II. Primers and sequences used in this study.

\begin{tabular}{ll} 
A, PCR primers & \\
\hline Name & \\
\hline circ-TIMP2 & \\
& \\
miR-185-5p & F: TGCGCATGTCTCTGATGCTT $\left(5^{\prime} \rightarrow 3^{\prime}\right)$ \\
& R: GGCCCTTTGAACATTTCTCTTTGA \\
MMP2 & F: ACACTCCAGCTGGGTGGAGAGAAAGGCAGT \\
& R: TGGTGTCGTGGAGTCG \\
Collagen-II & F: TACAGGATCATTGGCTACACACC \\
Aggrecan & R: GGTCACATCGCTCCAGACT \\
GAPDH & F: TGGACGATCAGGCGAAACC \\
& R: GCTGCGGATGCTCTCAATCT \\
U6 & F: CCCCTGCTATTTCATCGACCC \\
& R: GACACACGGCTCCACTTGAT \\
& F: GCACCGTCAAGGCTGAGAAC \\
& R: GGATCTCGCTCCTGGAAGATG \\
& F: CTCGCTTCGGCAGCACA
\end{tabular}

B, miRNA mimics and siRNAs

Name

miR-185-5p mimic

miR-185-5p si

circ-TIMP2 si

MMP2 si
Sequence $\left(5^{\prime} \rightarrow 3^{\prime}\right)$

UGGAGAGAAAGGCAGUUCCUGA

UCAGGAACUGCCUUUCUCUCCA

AGAGAAATGTTCAAAGGGCC

AGTTGGCAGTGCAATACCTGA

C, Probes for pull-down assay

Name

Sequence $\left(5^{\prime} \rightarrow 3^{\prime}\right)$

circ-TIMP2 pull-down probe

GGCCCTTTGAACATTTCTCTTTGATAAT

Random pull-down probe

TACGGATGTCTAGCGCTCTTGGGCTTTG

D, Probes for fluorescence in situ hybridization

\begin{tabular}{ll}
\hline Name & \\
\hline circ-TIMP2 & Sequence $\left(5^{\prime} \rightarrow 3^{\prime}\right)$ \\
miR-185-5p & GATTCTCCTTATCATTACCGAGAAAGTTCTTC \\
\hline
\end{tabular}

E, Probes for northern blotting

\begin{tabular}{ll}
\hline Name & \\
\hline miR-185-5p & Sequence $\left(5^{\prime} \rightarrow 3^{\prime}\right)$ \\
U6 & TCAGGAACTGCCTTTCTCTCCA \\
\hline
\end{tabular}

miR, microRNA; circ, circular RNA; TIMP2, tissue inhibitor of metalloproteinases 2; MMP, matrix metallopeptidase 2; si/siRNA, small interfering RNA; NC, negative control.

(Cytiva). Image 1.47 (National Institutes of Health) was used for densitometry analysis.
Pull-down assay with a biotinylated DNA probe. The pull-down assay was performed as previously described (32). 
The biotinylated DNA probe complementary to circ-TIMP2 (Table II) was added to $500 \mu 1$ lysis buffer $(0.5 \mathrm{M} \mathrm{NaCl}$, $20 \mathrm{mM}$ Tris- $\mathrm{HCl}$ and $1 \mathrm{mM}$ EDTA, $\mathrm{pH}$ 7.5), followed by incubation with streptavidin-coated magnetic beads at $25^{\circ} \mathrm{C}$ for $3 \mathrm{~h}$. Subsequently, the cell pellets were re-suspended with the lysis buffer ( $1 \mathrm{ml} / 100 \mathrm{mg}$ of cell pellet), and the cell lysates were incubated with the probe-coated beads. Finally, the RNA mixture was eluted and extracted for northern blot analysis by using a magnetic support to separate the beads from cell lysate, discarding the supernatant and washing the beads with $900 \mu \mathrm{l}$ wash buffer ( $0.5 \%$ SDS, 2 X SSC) five times interspersed with $5 \mathrm{~min}$ agitation on a rotator at room temperature.

Northern blotting. Digoxin-labeled probes were prepared with DIG Northern Starter kit (Roche Diagnostics GmbH) as previously described (33). Total RNA samples were resolved on $2 \%$ agarose or $15 \%$ polyacrylamide-urea gels and transferred to Hybond-N+ membranes (Amersham; Cytiva). The membranes were dried, crosslinked by ultraviolet irradiation $\left(265 \mathrm{~nm} ; 0.15 \mathrm{~J} / \mathrm{cm}^{2}\right)$, and subjected to hybridization with digoxin-labeled miR-185-5p probes at $65^{\circ} \mathrm{C}$ or $42^{\circ} \mathrm{C}$ overnight; digoxin-labeled U6 probes were used as controls (Table II). The blot was visualized on a ChemiDoc XRS system (Bio-Rad Laboratories, Inc.).

RNA immunoprecipitation (RIP). RIP was performed using a Magna RIP kit (EMD Millipore) according to the manufacturer's instructions. Briefly, $2 \times 10^{7} \mathrm{NP}$ cells were submitted to UV-crosslinking $\left(600 \mathrm{~mJ} / \mathrm{cm}^{2}\right)$ and lysed with $100 \mu \mathrm{l}$ RIP lysis buffer containing a proteinase inhibitor cocktail (Roche Diagnostics GmbH) and RNase inhibitor (Promega Corporation). Following incubation with DNase I (Roche Diagnostics $\mathrm{GmbH}$ ) at $37^{\circ} \mathrm{C}$ for $10 \mathrm{~min}$, the lysates were centrifuged at $12,000 \mathrm{x} \mathrm{g}$ at $4^{\circ} \mathrm{C}$ for $30 \mathrm{~min}$. The resulting supernatants were added to $900 \mu \mathrm{l}$ RIP immunoprecipitation buffer and incubated with $5 \mu \mathrm{g}$ anti-argonaute 2 (AGO2) antibodies pre-bound to magnetic beads for $3 \mathrm{~h}$. Subsequently, $20 \%$ of the immunoprecipitate was evaluated by western blotting, and the remaining $80 \%$ was treated with proteinase $\mathrm{K}$ at $37^{\circ} \mathrm{C}$ for $30 \mathrm{~min}$.

Statistical analysis. Each experiment was repeated at least three times, and cells in every experiment were harvested from a single isolation process. Continuous data are presented as the mean \pm standard deviation. GraphPad Prism version 7.0 (GraphPad Software, Inc.) or SPSS version 22.0 (IBM Corp.) was used for statistical analysis. Comparisons between two groups were performed by unpaired Student's t-test. Categorical data were analyzed by the $\chi^{2}$ test. Multi-group comparisons were performed using one-way ANOVA, and Tukey's test was used for the post hoc analysis. Pearson's correlation coefficients were determined to assess correlations of continuous data, and Spearman's rank correlation was used for ordinal data. $\mathrm{P}<0.05$ was considered to indicate a statistically significant difference.

\section{Results}

miR-185-5p is downregulated in degenerative NP tissues and regulates ECM synthesis. RT-qPCR results demonstrated that
miR-185-5p was significantly downregulated in degenerative NP tissues compared with that in the controls (Fig. 1A). Spearman's correlation analysis revealed that miR-185-5p was significantly negatively correlated with IDD grade $(\rho=-0.926$; $\mathrm{P}<0.001$; Fig. 1B). Next, the functions of miR-185-5p in NP cells were assessed. The results demonstrated that miR-185-5p mimics significantly increased the expression level of miR-185-5p in NP cells, whereas siRNA markedly decreased the expression level of miR-185-5p (Fig. 1C). NP cells transfected with the miR-185-5p mimic displayed increased expression levels of collagen II and aggrecan (Fig. 1D). These results indicated a pro-anabolic role of miR-185-5p in NP cells. Following treatment with TNF- $\alpha$ and IL-1 $\beta$, cultured NP cells exhibited significantly reduced expression levels of miR-185-5p compared with those in the untreated control group (Fig. 1E). The miR-185-5p mimic counteracted the TNF- $\alpha$ - and IL-1 $\beta$-induced inhibition of ECM production in NP cells (Fig. 1F and G). These results indicated that miR-185-5p positively regulated NP cell metabolism.

miR-185-5p exerts its function in NP cells via MMP2 inhibition. A previous study has demonstrated that miR-185 overexpression in vitro reduces MMP-2 levels (31). An increase in MMP2 expression was observed in degenerative NP tissues compared with that in the control samples (Fig. 2A). In addition, Pearson correlation analysis revealed that MMP-2 expression was significantly negatively correlated with miR-185-5p ( $r=-0.870 ; \mathrm{P}<0.001 ;$ Fig. $2 \mathrm{~B})$. As predicted by bioinformatics, MMP2, which is a catabolic factor, was a potential target of miR-185-5p (Fig. 2C). Transfection with the miR-185-5p mimic significantly decreased the luciferase activity of the wild-type MMP2 reporter compared with that in the control groups, whereas introducing mutations in the target site abolished this inhibitory effect (Fig. 2D). In addition, western blotting demonstrated a significant increase in MMP2 protein expression levels following treatment of NP cells with TNF- $\alpha$ and IL- $1 \beta$ compared with that in untreated cells, and this effect was attenuated by transfection with the miR-185-5p mimic (Fig. 2E and F). Next, the present study examined whether miR-185-5p and MMP2 were functionally related in NP cells. Fig. S1 demonstrates the transfection efficiency of the MMP-2 overexpression vector and MMP-2 siRNA analyzed by RT-qPCR in NP cells. As demonstrated in Fig. 2G and H, overexpression of MMP2 significantly attenuated the protective effects of miR-185-5p in NP cells treated with TNF- $\alpha$ and IL-1 $\beta$, suggesting that miR-185-5p regulated NP cell function by targeting MMP2.

circ-TIMP2 acts as an miR-185-5p sponge. miR-185-5p was predicted to have binding sites for circ-TIMP2. RT-qPCR results demonstrated that circ-TIMP2 expression levels were significantly higher in NP tissues from patients with IDD compared with those in the control samples (Fig. 3A and B). Pearson correlation analysis revealed that circ-TIMP2 expression was significantly negatively correlated with miR-185-5p ( $\mathrm{r}=-0.717$; Fig. 3C), and Spearman's correlation analysis demonstrated that circ-TIMP2 was positively correlated with IDD grade ( $\rho=0.818$; Fig. 3D). RNA-FISH analysis demonstrated that the fluorescent value of circ-TIMP2 was evaluated in NP samples from patients with IDD, which indicated the 

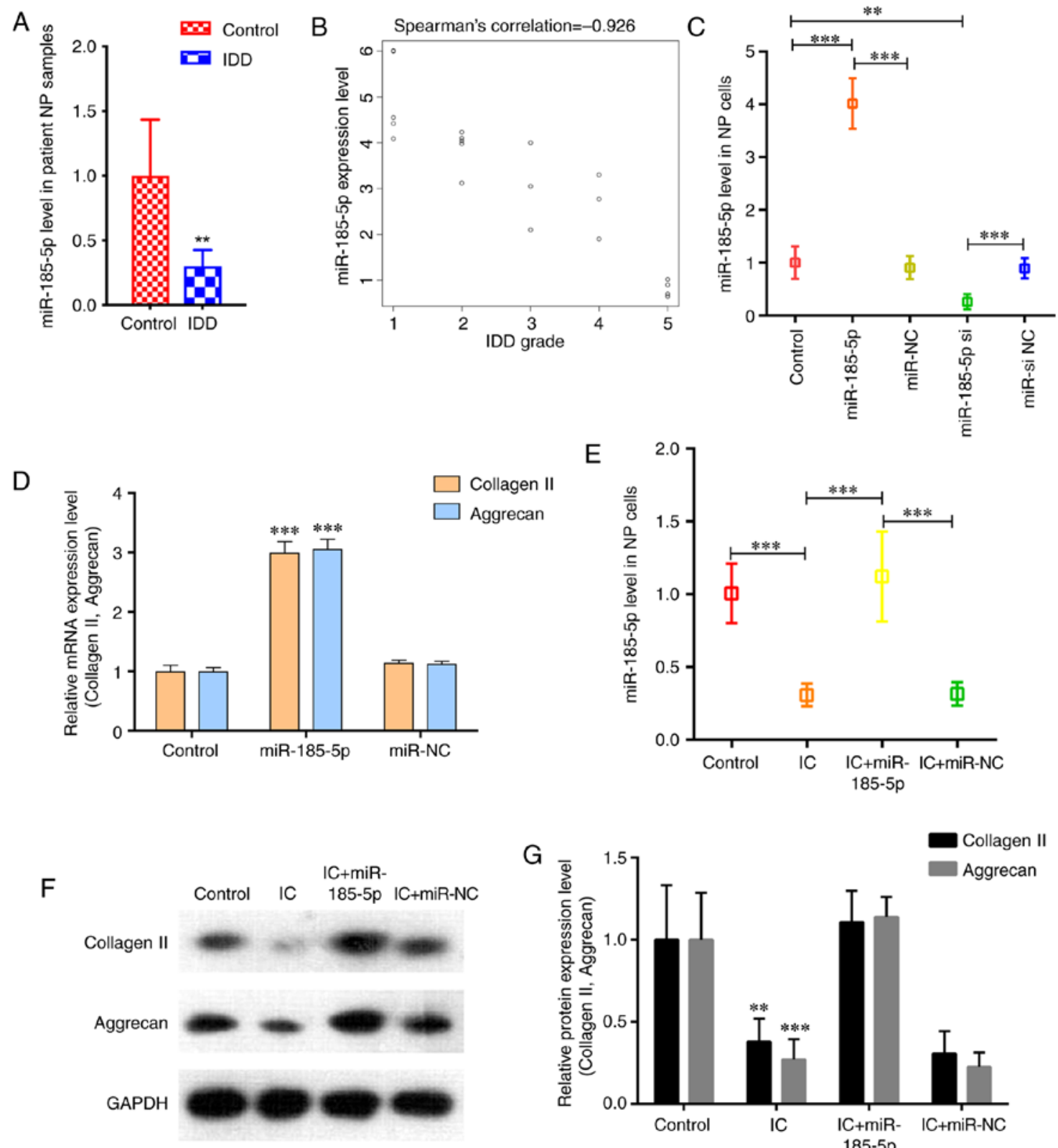

Collagen II Aggrecan
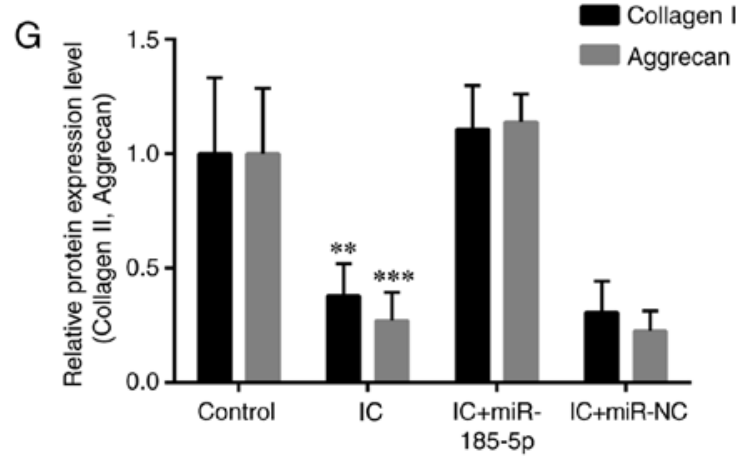

Figure 1. miR-185-5p is downregulated in degenerative NP tissues and involved in the regulation of NP cell function. (A) RT-qPCR analysis confirmed the downregulation of miR-185-5p in degenerative NP samples from patients with IDD compared with the control group. $n=10$. ${ }^{* *} \mathrm{P}<0.01 \mathrm{vs}$. control. (B) miR-185-5p expression was significantly negatively correlated with IDD grade ( $\mathrm{P}<0.001)$. (C) NP cells were transfected with the miR-185-5p mimic, miR-NC, miR-185-5p si or miR-si NC, and miR-185-5p levels in NP cells were analyzed by RT-qPCR. ${ }^{* *} \mathrm{P}<0.01,{ }^{* * *} \mathrm{P}<0.001$. (D) RT-qPCR was performed to analyze the mRNA expression levels of collagen II and aggrecan in NP cells after transfection with miR-185-5p. (E) NP cells were transfected with the miR-185-5p mimic or miR-NC and treated with ICs (interleukin $1 \beta$ and tumor necrosis factor- $\alpha$ ). RT-qPCR demonstrated decreased miR-185-5p levels in NP cells treated with ICs, which was reversed by transfection with miR-185-5p mimic. ${ }^{* * * *} \mathrm{P}<0.001$. (F and G) Western blot analysis demonstrated that miR-185-5p attenuated the catabolic response and reversed the decreased expression of ECM components induced by IC treatment in NP cells compared with the control group. ${ }^{\text {** }} \mathrm{P}<0.01$, ${ }^{* * * *} \mathrm{P}<0.001$ vs. control. miR, microRNA; NP, nucleus pulposus; IDD, intervertebral disc degeneration; RT-qPCR, reverse transcription-quantitative PCR; si, small interfering RNA; NC, negative control; IC, inflammatory cytokine.

circ-TIMP2 expression level was increased in IDD NP samples compared with that in the normal controls (Fig. 3E). To further assess the interaction between circ-TIMP2 and miR-185-5p, the predicted binding sites of circ-TIMP2 and a mutated sequence were constructed downstream of the firefly luciferase gene to yield wild-type and mutant pGL3-circ-TIMP2, respectively. These plasmids were co-transfected with the miR-185-5p mimic or miR-NC into NP cells, and the results demonstrated that transfection with the miR-185-5p mimic reduced luciferase activity of wild-type pGL3-circ-TIMP2 compared with that in NP cells transfected with miR-NC. However, luciferase activities of the mutant pGL3-circ-TIMP2 were comparable between the miR-185-5p mimic and NC groups (Fig. 3F and G). RNA-FISH results demonstrated that circ-TIMP2 and miR-185-5p were co-localized in the NP cell cytoplasm (Fig. 3H). RIP confirmed that anti-AGO2 antibodies immunoprecipitated circ-TIMP2 (Fig. 3I). In addition, Northern blot analysis revealed that circ-TIMP2 pulled down miR-185-5p (Fig. 3J). Taken together, these results suggested that circ-TIMP2 could directly bind miR-185-5p in NP cells. 
A

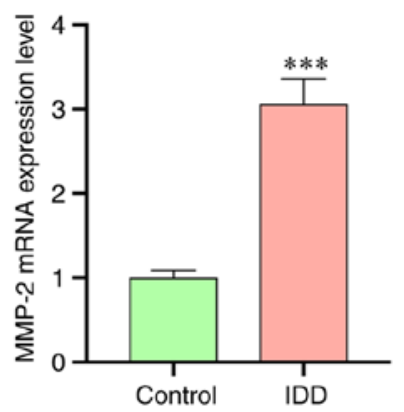

B

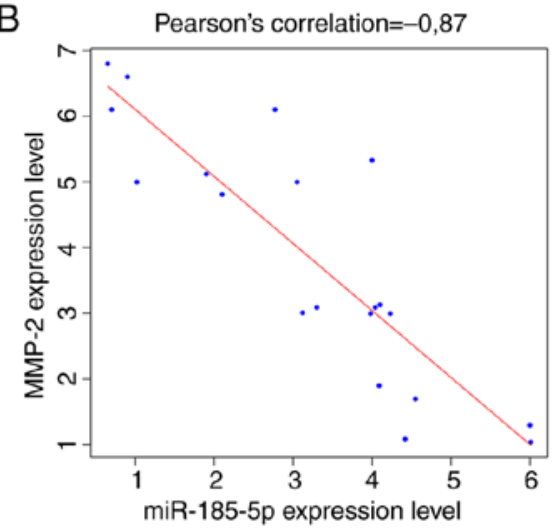

E

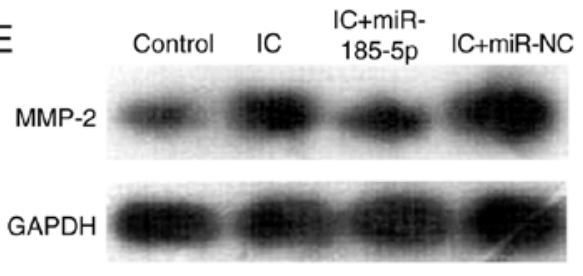

G IC+miR-185-5p+ Control MMP-2 OE MMP-2 NC

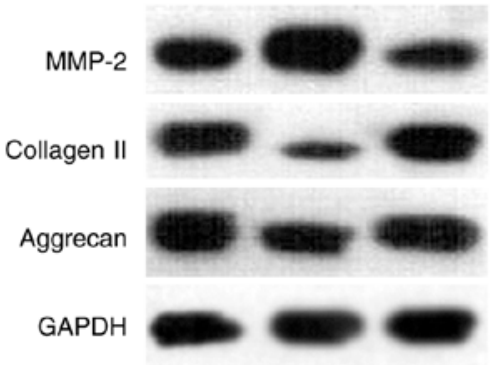

C

\author{
MMP-2 3'UTR wild $\quad 5^{\prime}$...ucccacaggccuucCUCUCCac...3' \\ miR-185-5p $3^{\prime}$ aguccuugacggaaaGAGAGGu 5'
}

MMP-2 $3^{\prime}$ UTR mutant $\quad 5^{\prime}$...ucccacaggccuucGAGAGGac...3'

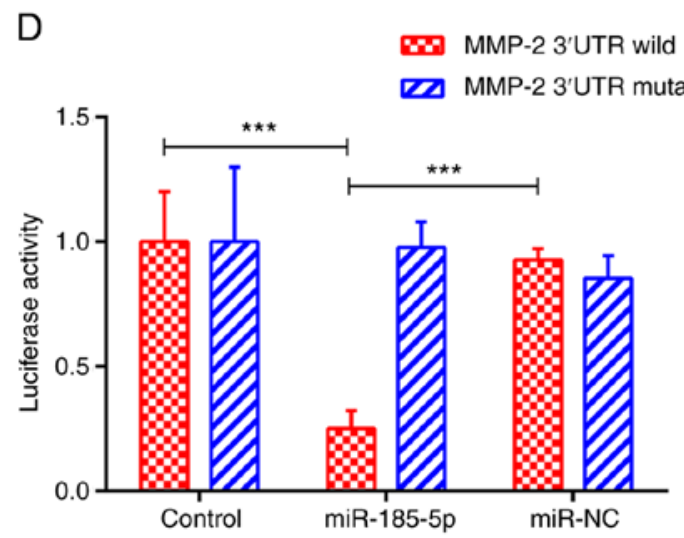

$\mathrm{F}$

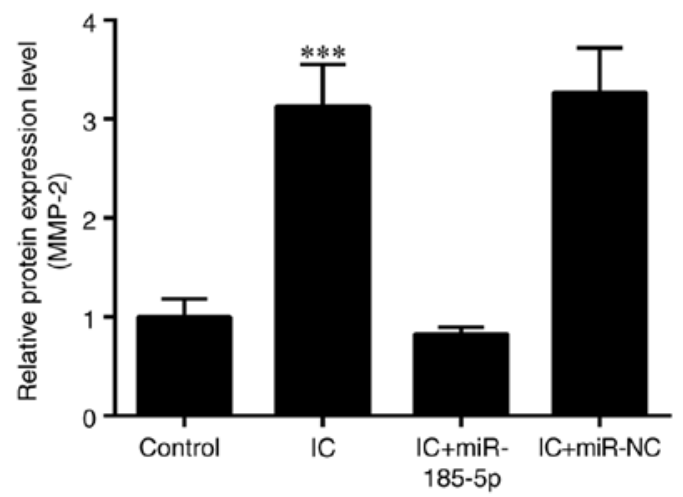

$\mathrm{H}$

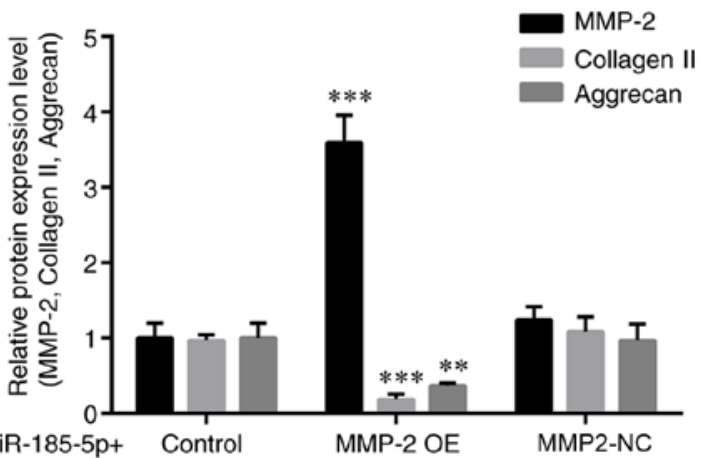

Figure 2. miR-185-5p regulates NP cell function by inhibiting its target MMP2. (A) RT-qPCR analysis revealed higher expression of MMP2 in degenerative NP tissues from patients with IDD compared with that in the controls. ${ }^{* * *} \mathrm{P}<0.001$ vs. control. (B) MMP-2 expression was significantly negatively correlated with miR-185-5p expression ( $\mathrm{P}<0.001)$. (C) Sequence alignment of human miR-185-5p and the 3'-UTR region of MMP2 mRNA. Mutations were introduced in the 3'-UTR of the MMP2 sequence to create mutant luciferase reporter constructs. (D) Luciferase reporter assay in NP cells after transfection with miR-NC or the miR-185-5p mimic, Renilla luciferase vector pRL-SV40 and the reporter constructs. Firefly and Renilla luciferase activities were measured in the same sample, and firefly luciferase signals were normalized to Renilla luciferase signals. ${ }^{* * *} \mathrm{P}<0.001$. (E and F) NP cells were transfected with the miR-185-5p mimic or miR-NC and treated with ICs (interleukin $1 \beta$ and tumor necrosis factor $\alpha$ ). Western blot analysis demonstrated an increase in MMP2 expression in NP cells treated with ICs compared with that in the control group, which was alleviated by transfection with the miR-185-5p mimic. ${ }^{* * *} \mathrm{P}<0.001$. (G and $\left.\mathrm{H}\right)$ Western blotting was used to analyze the protein expression of extracellular matrix components (collagen II and aggrecan) in NP cells. Overexpression of MMP2 interfered with the protective effects of miR-185-5p mimic on the expression of these functional proteins in IC-treated NP cells. ${ }^{* *} \mathrm{P}<0.01,{ }^{* * * *} \mathrm{P}<0.001 . \mathrm{MMP} 2$, matrix metallopeptidase 2; miR, microRNA; NP, nucleus pulposus; IDD, intervertebral disc degeneration; RT-qPCR, reverse transcription-quantitative PCR; UTR, untranslated region; OE, overexpression vector; NC, negative control; IC, inflammatory cytokine.

circ-TIMP2 modulates NP cell function by targeting miR-185-5p and MMP2. As presented in Fig. 4A, RT-qPCR results demonstrated that compared with the levels in NP cells transfected with circ-NC, transfection with a circ-TIMP2 overexpression plasmid resulted in increased circ-TIMP2 expression levels, which were significantly reduced by siRNA 
A

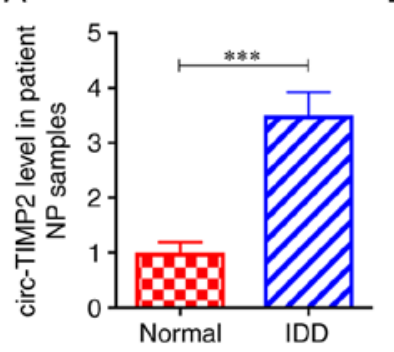

D

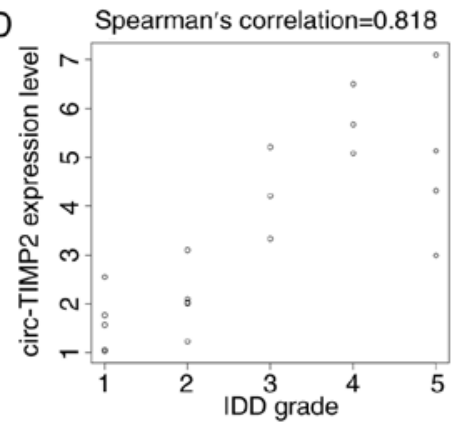

$\mathrm{F}$

circ-TIMP2 3'UTR wild $5^{\prime}$...tatagtttaagaaggCTCTCCA...3'

miR-185-5p $\quad 3^{\prime}$....agtccttgacggaaaGAGAGGT $5^{\prime}$

circ-TIMP2 $3^{\prime}$ UTR mutant $\quad 5^{\prime}$...tatagtttaagaaggGAGAGGT....3'

G

$\infty$ circ-TIMP2 3'UTR wild

Z circ-TIMP2 3'UTR mutant
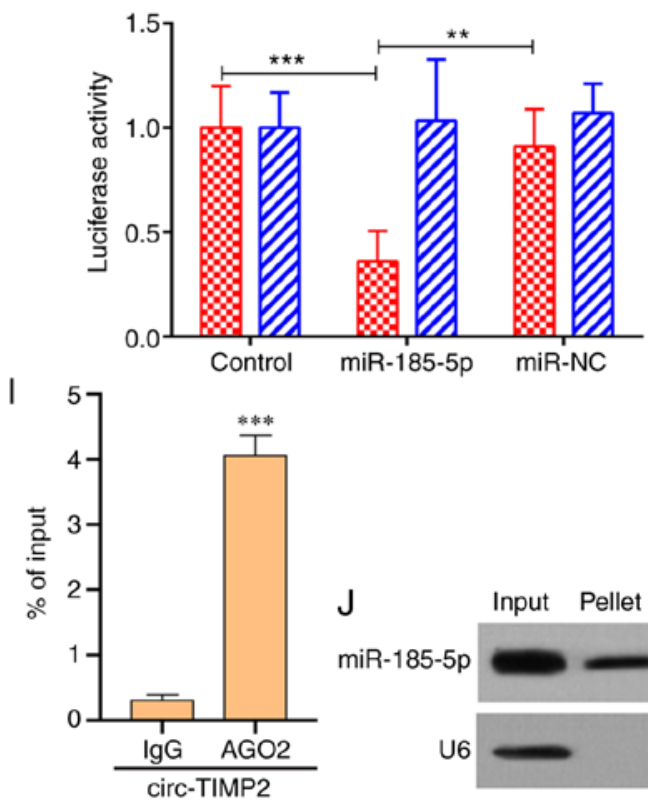

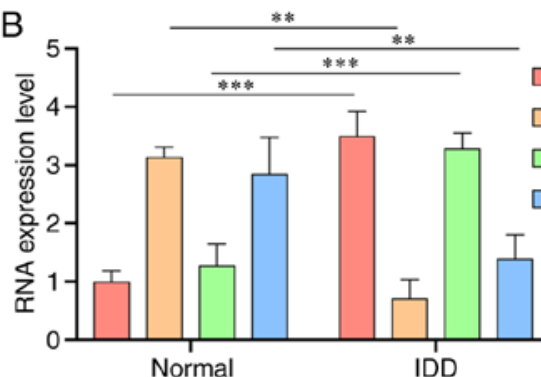

E
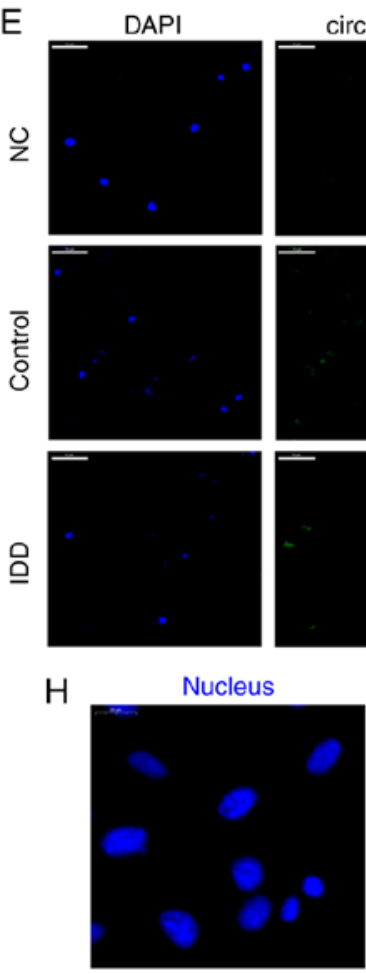

miR-185-5p
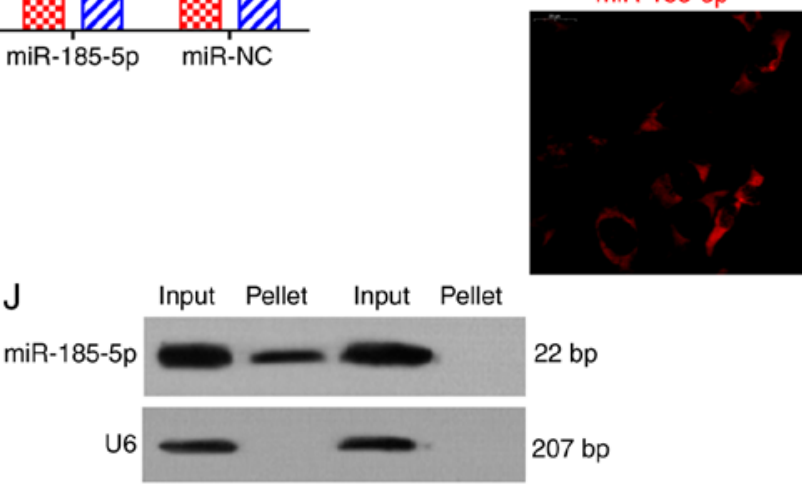

circ-TIMP2 probe Random probe

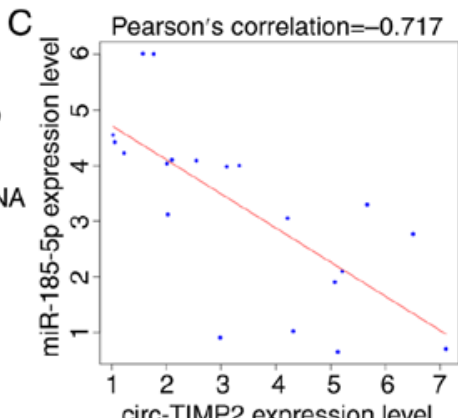

circ-TIMP2 expression level
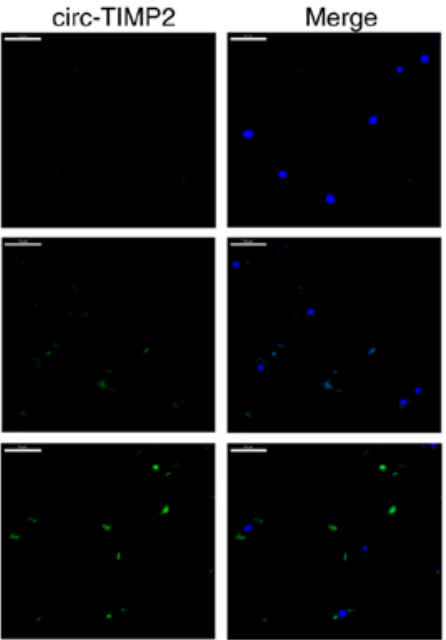

circ-TIMP2

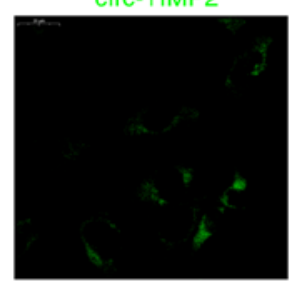

Merge

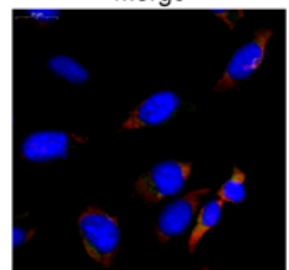

Figure 3. circ-TIMP2 acts as a miR-185-5p sponge. (A) circ-TIMP2 levels in NP samples from patients with IDD or controls were determined by RT-qPCR $\mathrm{n}=10{ }^{* * * *} \mathrm{P}<0.001$. (B) mRNA expression levels of circ-TIMP2, miR-185-5p, MMP2 and TIMP2 in patients with IDD and controls were determined by RT-qPCR ${ }^{* *} \mathrm{P}<0.01,{ }^{* * *} \mathrm{P}<0.001$. (C) circ-TIMP2 expression was significantly negatively correlated with miR-185-5p expression level (P<0.001). (D) circ-TIMP2 expression was significantly negatively correlated with IDD grade $(\mathrm{P}<0.001)$. (E) The expression of circ-TIMP2 was evaluated in NP samples from patients with IDD and controls by RNA-FISH. The circ-TIMP2 probe was labeled with Alexa Fluor ${ }^{\circledR} 488$. Nuclei were stained with DAPI. Scale bar, $50 \mu \mathrm{m}$. (F) Sequence alignment of human miR-185-5p with circ-TIMP2. Mutations were introduced in the circ-TIMP2 sequence to create the mutant luciferase reporter constructs. (G) Luciferase reporter assay in NP cells after transfection with miR-NC or the miR-185-5p mimic, Renilla luciferase vector pRL-SV40 and the reporter constructs. Firefly and Renilla luciferase activities were measured in the same sample, and firefly luciferase signals were normalized to Renilla luciferase signals. ${ }^{* *} \mathrm{P}<0.01,{ }^{* * *} \mathrm{P}<0.001$. (H) RNA-FISH analysis of co-localization of circ-TIMP2 and miR-185-5p in the cytoplasm of NP cells. circ-TIMP2 and miR-185-5p probes were labeled with Alexa Fluor ${ }^{\circledR} 488$ and Cy3, respectively. Nuclei were stained with DAPI. Scale bar, $20 \mu \mathrm{m}$. (I) RNA immunoprecipitation confirmed that anti-AGO2 antibodies immunoprecipitated circ-TIMP2. ${ }^{* * *} \mathrm{P}<0.001$ vs. IgG. (J) miR-185-5p was pulled down by the circular probe for circ-TIMP2 but not by a random probe. The levels of miR-185-5p were evaluated by northern blotting. Input, 20\% samples were loaded; pellet, all samples were loaded. MMP2, matrix metallopeptidase 2; miR, microRNA; NP, nucleus pulposus; IDD, intervertebral disc degeneration; RT-qPCR, reverse transcription-quantitative PCR; circ, circular RNA; TIMP2, tissue inhibitor of metalloproteinases 2; FISH, fluorescence in situ hybridization; UTR, untranslated region; NC, negative control; $\mathrm{IgG}$, immunoglobulin G; AGO2, argonaute 2 . 
A

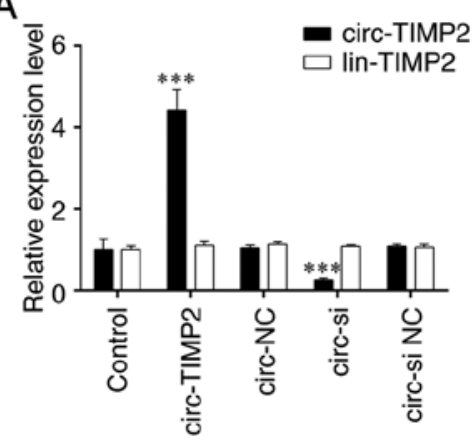

B

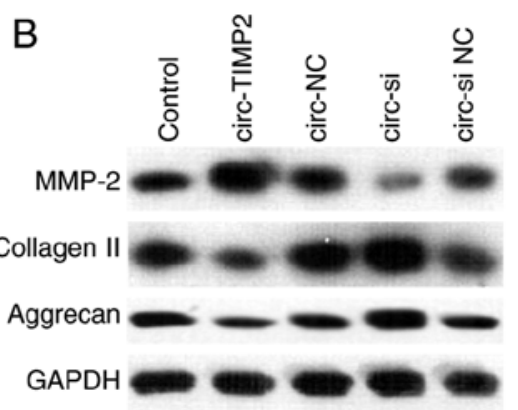

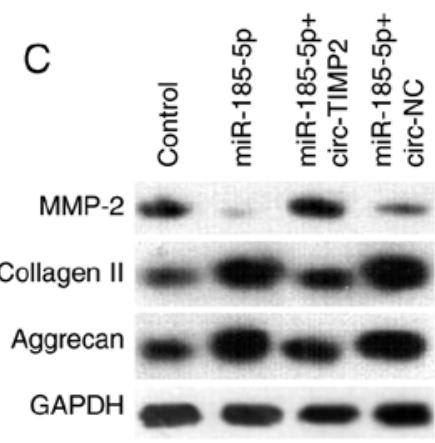

Figure 4. circ-TIMP2 functions in NP cells by targeting miR-185-5p and MMP2. (A) NP cells were transfected with circ-TIMP2, circ-NC, circ-si or circ-si NC, and circ-TIMP2 levels were analyzed by reverse transcription-quantitative PCR. ${ }^{* * *} \mathrm{P}<0.001$ circ-TIMP2 vs. circ-NC or circ-si vs. circ-si NC. (B) NP cells were transfected with circ-TIMP2, circ-NC, circ-si or circ-si NC, and MMP2 expression was analyzed by western blotting. The protein expression of MMP2 was enhanced after circ-TIMP2 overexpression and reduced following circ-TIMP2 knockdown. (C) NP cells were co-transfected with miR-185-5p and circ-TIMP2 or circ-NC. Western blot analysis demonstrated that circ-TIMP2 blocked the inhibitory effect of miR-185-5p on MMP2 expression. MMP2, matrix metallopeptidase 2; miR, microRNA; NP, nucleus pulposus; circ, circular RNA; lin, linear RNA; TIMP2, tissue inhibitor of metalloproteinases 2; si, small interfering RNA; circ-si, circ-TIMP2 siRNA; NC, negative control.

silencing. Next, western blotting was used to assess the effect of circ-TIMP2 on MMP2 expression. Overexpression of circ-TIMP2 in NP cells increased MMP2 expression, whereas circ-TIMP2 knockdown had the opposite effect (Fig. 4B). In addition, circ-TIMP2 overexpression reversed the inhibitory effect of miR-185-5p on MMP2 expression in NP cells (Fig. 4C). Taken together, these results indicated that circ-TIMP2 functioned as an miR-185-5p sponge to regulate MMP2 expression in NP cells. The function of circ-TIMP2 in NP cells after treatment with TNF- $\alpha$ and IL-1 $\beta$ was further examined; following administration of these ICs, RT-qPCR demonstrated upregulation of circ-TIMP2 expression and downregulation of miR-185-5p expression in NP cells; however, both effects were reversed by circ-TIMP2 knockdown (Fig. 5A and B). Knockdown of circ-TIMP2 decreased the protein expression levels of MMP2 in IC-treated NPs compared with those in NPs treated with IC and si NC (Fig. 5C and D). To assess whether MMP2 was a downstream mediator of circ-TIMP2 in IC-treated NP cells, NP cells were co-transfected with circ-TIMP2 and MMP2 siRNA; the results demonstrated that MMP2 silencing significantly attenuated the effects of circ-TIMP2 on inhibiting collagen-II and aggrecan expression in NP cells treated with TNF- $\alpha$ and IL-1 $\beta$ (Fig. 5E and F). Collectively, these results suggested that circ-TIMP2 functioned in NP cells via modulation of miR-185-5p and MMP2 expression.

\section{Discussion}

Previous studies have indicated that certain miRNAs are dysregulated in the development and progression of IDD and serve vital roles by targeting distinct genes that regulate NP cell function $(16,34,35)$. The present study firstly identified miR-185-5p as a key miRNA involved in IDD that regulates the balance between anabolic and catabolic factors in NP cells. Of note, the results of the present study revealed that MMP2 was a direct target gene of miR-185-5p in NP cells. Next, whether circRNAs affected the regulatory functions of miR-185-5p in NP cells was examined by RT-qPCR, and the results demonstrated that circ-TIMP2 levels were decreased in NP tissues from patients with IDD compared with controls. In addition, the results demonstrated that circ-TIMP2 significantly inhibited the effects of miR-185-5p and suppressed its function by direct binding. These findings suggested that circ-TIMP2 may act as a miR-185-5p sponge to promote ECM catabolism and suppress ECM anabolism in NP cells, which may consequently accelerate IDD progression.

Dysregulation of miR-185-5p has been observed in various types of tumors, such as colon and breast cancer $(36,37)$. To date, the role of miR-185-5p in the development and progression of IDD remains unclear. In the present study, miR-185-5p expression levels were significantly lower in degenerative NP tissues compared with those in the control tissues, as confirmed by RT-qPCR analysis. Accumulating evidence suggests that a variety of cellular events are dysregulated in IDD progression, including NP cell apoptosis, ECM degradation and proinflammatory cytokine expression (38-41). A previous study has demonstrated that excessive apoptosis of intervertebral disc cells serves a crucial role in IDD pathogenesis (38). In addition, loss of collagen II is an early sign of IDD $(42,43)$. Aggrecan, as the main proteoglycan in NP tissues, is also crucial to normal disc function $(44,45)$.

The hallmark of IDD is a progressive loss of the ECM macromolecules aggrecan and collagen II (42). To further examine the function of miR-185-5p in IDD pathogenesis, a series of experiments were performed to assess the association between miR-185-5p and NP cell function. Transfection with the miR-185-5p mimic markedly enhanced collagen II and aggrecan levels in NP cells, which suggested that miR-185-5p may serve a role in the development of IDD by affecting ECM composition. The present study also aimed to identify the possible target genes of miR-185-5p that are implicated in IDD pathogenesis. Of note, high expression levels of MMP2 were observed in degenerative NP tissues, and bioinformatics analysis demonstrated that MMP2 was a potential target gene of miR-185-5p. In addition, previous studies have reported that MMP2 degrades ECM components such as collagen II and aggrecan $(34,46)$. In the present study, MMP2 was confirmed as a direct target of miR-185-5p by luciferase assay and western blotting. MMPs are crucial players in tissue remodeling and 
A
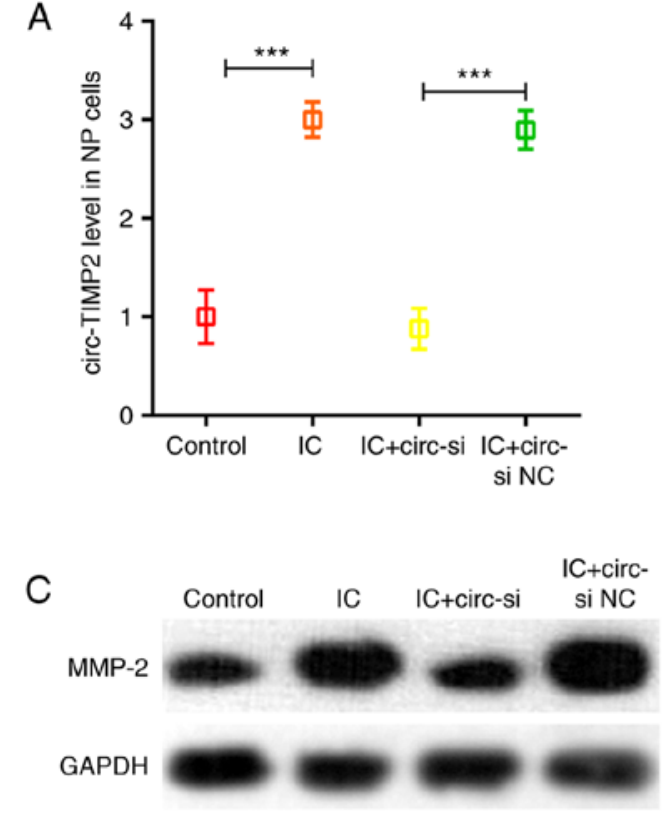

E

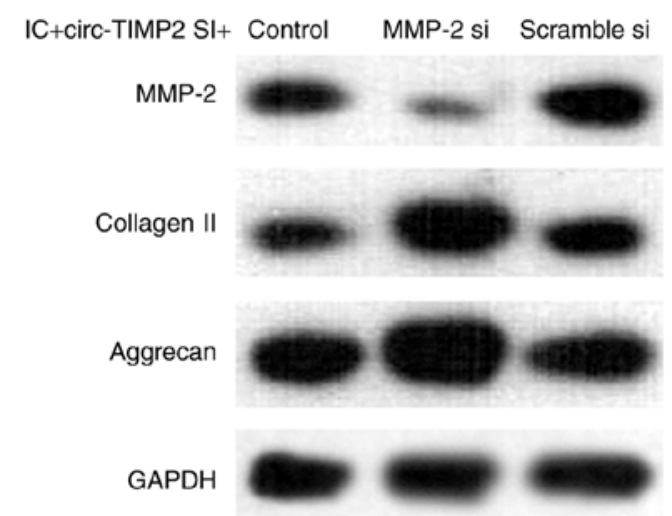

B
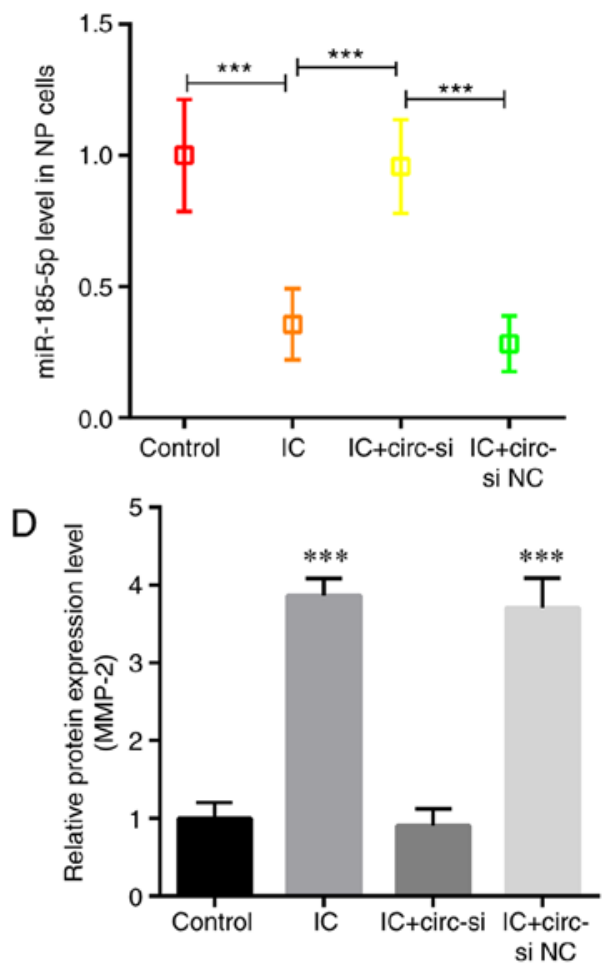

$\mathrm{F}$

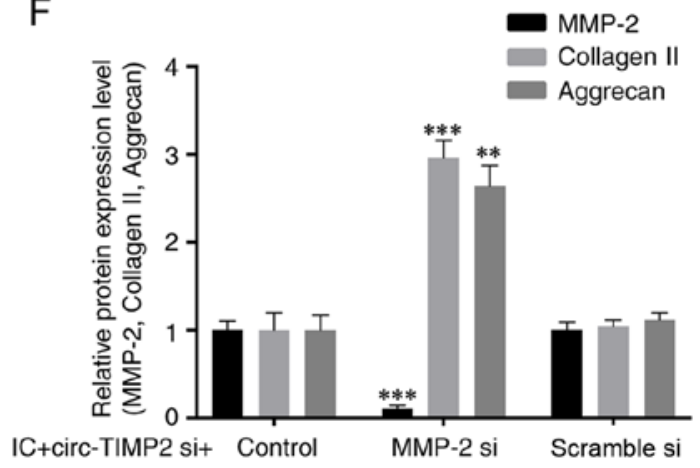

Figure 5. Function of circ-TIMP2 in NP cells after treatment with tumor necrosis factor $\alpha$ and interleukin-1 $\beta$. (A) RT-qPCR analysis demonstrated an increase in circ-TIMP2 expression in NP cells treated with IC, which was reversed by transfection with circ-si. ${ }^{* * *} \mathrm{P}<0.001$. (B) RT-qPCR analysis demonstrated a decrease in miR-185-5p levels in NP cells treated with IC, which was reversed by transfection with circ-si. ${ }^{* * *} \mathrm{P}<0.001$. (C and D) Western blotting demonstrated that transfection with circ-si reduced the IC-induced increase of MMP 2 expression compared with that in si NC-transfected cells. ${ }^{* * *} \mathrm{P}<0.001$ vs. IC + circ-si NC. (E and F) Western blotting was used to analyze the protein expression of MMP2 and extracellular matrix components (collagen II and aggrecan) in NP cells. Knockdown of MMP2 impaired the effect of circ-si on the expression of these functional proteins in IC-treated NP cells. ${ }^{* *} \mathrm{P}<0.01,{ }^{* * *} \mathrm{P}<0.001$ vs. scramble si. circ-TIMP2, circular RNA derived from tissue inhibitor of metalloproteinases 2; MMP2, matrix metallopeptidase 2; miR, microRNA; NP, nucleus pulposus; si, small interfering RNA; circ-si, circ-TIMP2 siRNA; NC, negative control; IC, inflammatory cytokine.

repair, and elevated MMP levels in the intervertebral disc catabolize ECM constituents, causing IDD (47,48). MMPs (such as MMP2), which are zinc- and calcium-dependent endopeptidases, participate in ECM degradation and remodeling (49). Similar to TNF- $\alpha$, overexpression of MMP2 has been demonstrated to enhance the degradation of ECM components in NP cells $(12,50)$. The present study demonstrated that reduced miR-185-5p levels resulted in enhanced MMP2 expression, with subsequent degradation of ECM constituents, including collagen II and aggrecan.

As predicted by starBase, circ-TIMP2 was demonstrated to possess binding sites for miR-185-5p, which was confirmed in the present study by luciferase reporter, RNA pull-down, RIP and RNA-FISH assays. In addition, the mRNA expression of the miR-185-5p target MMP2 was positively regulated by circ-TIMP 2 . In the present study, TNF- $\alpha$ and IL- $1 \beta$ were selected as agents to induce a range of pathogenic responses in NP cells, as they serve central roles in the pathological process of IDD $(11,14,51)$. Stimulation of NP cells with these cytokines causes a pattern of changes similar to that observed in patients with IDD (12). TNF- $\alpha$ and IL- $1 \beta$ accumulation is considered to facilitate ECM degradation via extrinsic and intrinsic pathways $(14,51)$. In the present study, stimulation of NP cells with TNF- $\alpha$ and IL- $1 \beta$ led to similar effects to those previously observed in patients with IDD, including increased expression levels of the ECM-degrading enzyme MMP2 and decreased levels of the ECM components collagen II and aggrecan $(12,52)$. MMP2 silencing remarkably impaired the proinflammatory ability of circ-TIMP2, confirming MMP2 as a direct target gene of circ-TIMP 2 and miR-185-5p. In addition, 
MMP2 silencing inhibited circ-TIMP2, which enhanced the TNF- $\alpha$ - and IL-1 $\beta$-induced effects in NP cells.

The role of mir-185-5p in IDD is relatively unclear. A recent study by Zhang et al (53) demonstrated that miR-185-5p and other miRNAs may affect IDD development by co-regulating the expression of glycogen synthase kinase $3 \beta$. In the present study, mir-185-5p was identified as a key miRNA in the IDD process, providing a theoretical basis for developing novel optimized treatment regimens for IDD.

The present study had certain limitations. First, the newest classification method of disc degeneration described by Riesenburger et al (54) was not applied. The novel method is more elaborate and complex compared with the one applied in the present study, and its implementation is difficult and error-prone. In addition, the present study did not assess fragments per kilobase of transcript per million mapped reads values, since no RNA-seq was performed. Furthermore, this was a single-center study, with potential selection bias. Additionally, the mechanism underlying circ-TIMP2 upregulation in IDD remains largely unclear. Therefore, well-designed multicenter studies are warranted to confirm the present findings and to comprehensively assess the role of circ-TIMP2 in IDD.

In summary, the results of the present study demonstrated that circ-TIMP2 promotes TNF- $\alpha$ - and IL-1 $\beta$-induced NP cell imbalance between ECM anabolism and catabolism via miR-185-5p-MMP2 signaling. These results provide a potential therapeutic option for the treatment of IDD.

\section{Acknowledgements}

Not applicable.

\section{Funding}

This study was supported by the National Natural Science Foundation of China (grant no. 881802197) and the Natural Science Foundation of Hebei (grant no. H2019110028).

\section{Availability of data and materials}

The data generated or analyzed during the present study are included in this published article with the exception of the siRNA sequences, which are patented.

\section{Authors' contributions}

WG conceived the study. BZ, KM, CS, HQD and WXL conducted the experiments. WG, LZ and HRL analyzed the data. WG, ZYD and QC interpreted the data. WG and BZ obtained funding. WG wrote the manuscript with the help of the other authors. All authors read and approved the final manuscript.

\section{Ethics approval and consent to participate}

This study was approved by the ethics committees of Tianjin Medical University General Hospital and Hebei Province Cangzhou Hospital of Integrated Traditional and Western Medicine. Written informed consent was obtained from all patients for the use of their tissue specimens for research purpose.

\section{Patient consent for publication}

Not applicable.

\section{Competing interests}

The authors declare that they have no competing interests.

\section{References}

1. Ravindra VM, Senglaub SS, Rattani A, Dewan MC, Härtl R, Bisson E, Park KB and Shrime MG: Degenerative lumbar spine disease: Estimating global incidence and worldwide volume. Global Spine J 8: 784-794, 2018.

2. Buckwalter JA: Aging and degeneration of the human intervertebral disc. Spine (Phila Pa 1976) 20: 1307-1314, 1995.

3. Costi JJ, Stokes IA, Gardner-Morse MG and Iatridis JC: Frequency-dependent behavior of the intervertebral disc in response to each of six degree of freedom dynamic loading: Solid phase and fluid phase contributions. Spine (Phila Pa 1976) 33: 1731-1738, 2008

4. Kalichman L and Hunter DJ: The genetics of intervertebral disc degeneration. Familial predisposition and heritability estimation. Joint Bone Spine 75: 383-387, 2008.

5. Samartzis D, Karppinen J, Mok F, Fong DY, Luk KD and Cheung KM: A population-based study of juvenile disc degeneration and its association with overweight and obesity, low back pain, and diminished functional status. J Bone Joint Surg Am 93: 662-670, 2011.

6. Friedman BW, O'Mahony S, Mulvey L, Mulvey L, Davitt M, Choi H, Xia S, Esses D, Bijur PE and Gallaghe EJ: One-week and 3-month outcomes after an emergency department visit for undifferentiated musculoskeletal low back pain. Ann Emerg Med 59: 128-133.e3, 2012.

7. Berg EJ and Ashurst JV: Anatomy, back, cauda equina. In: StatPearls, Treasure Island (FL), 2020.

8. Kepler CK, Markova DZ, Hilibrand AS, Vaccaro AR, Risbud MV Albert TJ and Anderson DG: Substance $\mathrm{P}$ stimulates production of inflammatory cytokines in human disc cells. Spine (Phila $\mathrm{Pa}$ 1976) 38: E1291-E1299, 2013.

9. Kepler CK, Markova DZ, Dibra F, Yadla S, Vaccaro AR, Risbud MV, Albert TJ and Anderson DG: Expression and relationship of proinflammatory chemokine RANTES/CCL5 and cytokine IL-1 $\beta$ in painful human intervertebral discs. Spine (Phila Pa 1976) 38: 873-880, 2013.

10. Adams MA, Freeman BJ, Morrison HP, Nelson IW and Dolan P: Mechanical initiation of intervertebral disc degeneration. Spine (Phila Pa 1976) 25: 1625-1636, 2000.

11. Dudek M, Yang N, Ruckshanthi JP, Williams J, Borysiewicz E, Wang P, Adamson A, Li J, Bateman JF, White MR, et al: The intervertebral disc contains intrinsic circadian clocks that are regulated by age and cytokines and linked to degeneration. Ann Rheum Dis 76: 576-584, 2017.

12. Wang J, Markova D, Anderson DG, Zheng Z, Shapiro IM and Risbud MV: TNF- $\alpha$ and IL- $1 \beta$ promote a disintegrin-like and metalloprotease with thrombospondin type I motif-5-mediated aggrecan degradation through syndecan-4 in intervertebral disc. J Biol Chem 286: 39738-39749, 2011.

13. Johnson ZI, Schoepflin ZR, Choi H, Shapiro IM and Risbud MV: Disc in flames: Roles of TNF- $\alpha$ and IL-1 $\beta$ in intervertebral disc degeneration. Eur Cell Mater 30: 104-116, 2015.

14. Risbud MV and Shapiro IM: Role of cytokines in intervertebral disc degeneration: Pain and disc content. Nat Rev Rheumatol 10: 44-56, 2014.

15. Lan PH, Liu ZH, Pei YJ, Wu ZG, Yu Y, Yang YF, Liu X, Che L, Ma CJ, Xie YK, et al: Landscape of RNAs in human lumbar disc degeneration. Oncotarget 7: 63166-63176, 2016.

16. Xu YQ, Zhang ZH, Zheng YF and Feng SQ: Dysregulated miR-133a mediates loss of type II collagen by directly targeting matrix metalloproteinase 9 (MMP9) in human intervertebral disc degeneration. Spine (Phila Pa 1976) 41: E717-E724, 2016. 
17. Memczak S, Jens M, Elefsinioti A, Torti F, Krueger J, Rybak A Maier L, Mackowiak SD, Gregersen LH, Munschauer M, et al: Circular RNAs are a large class of animal RNAs with regulatory potency. Nature 495: 333-338, 2013.

18. Wilusz JE and Sharp PA: Molecular biology. A circuitous route to noncoding RNA. Science 340: 440-441, 2013.

19. Salmena L, Poliseno L, Tay Y, Kats L and Pandolfi PP: A ceRNA hypothesis: The rosetta stone of a hidden RNA language? Cell 146: 353-358, 2011

20. Tang B, Hao Z, Zhu Y, Zhang H and Li G: Genome-wide identification and functional analysis of circRNAs in Zea mays. PLoS One 13: e0202375, 2018.

21. Ashwal-Fluss R, Meyer M, Pamudurti NR, Ivanov A, Bartok O, Hanan M, Evantal N, Memczak S, Rajewsky N and Kadener S: circRNA biogenesis competes with pre-mRNA splicing. Mol Cell 56: 55-66, 2014.

22. Vicens Q and Westhof E: Biogenesis of circular RNAs. Cell 159: 13-14, 2014.

23. Zhang XO, Wang HB, Zhang Y, Lu X, Chen LL and Yang L: Complementary sequence-mediated exon circularization. Cell 159: 134-147, 2014

24. Hansen TB, Jensen TI, Clausen BH, Bramsen JB, Finsen B, Damgaard CK and Kjems J: Natural RNA circles function as efficient microRNA sponges. Nature 495: 384-388, 2013.

25. Guo W, Zhang B, Mu K, Feng SQ, Dong ZY, Ning GZ, Li HR, Liu S, Zhao L, Li Y, et al: Circular RNA GRB10 as a competitive endogenous RNA regulating nucleus pulposus cells death in degenerative intervertebral disk. Cell Death Dis 9: 319, 2018

26. Pfirrmann CW, Metzdorf A, Zanetti M, Hodler J and Boos N Magnetic resonance classification of lumbar intervertebral disc degeneration. Spine (Phila Pa 1976) 26: 1873-1878, 2001.

27. Middendorp M, Vogl TJ, Kollias K, Kafchitsas K, Khan MF and Maataoui A: Association between intervertebral disc degeneration and the oswestry disability index. J Back Musculoskelet Rehabil 30: 819-823, 2017.

28. Urrutia J, Besa P, Campos M, Cikutovic P, Cabezon M, Molina M and Cruz JP: The Pfirrmann classification of lumbar intervertebral disc degeneration: An independent inter- and intra-observer agreement assessment. Eur Spine J 25: 2728-2733, 2016.

29. Livak KJ and Schmittgen TD: Analysis of relative gene expression data using real-time quantitative PCR and the 2(-Delta Delta C(T)) method. Methods 25: 402-408, 2001.

30. Vautrot V, Aigueperse C, Branlant C and Behm-Ansmant I: Fluorescence in situ hybridization of small non-coding RNAs. Methods Mol Biol 1296: 73-83, 2015.

31. Li JH, Liu S, Zhou H, Qu LH and Yang JH: StarBase v2.0 Decoding miRNA-ceRNA, miRNA-ncRNA and protein-RNA interaction networks from large-scale CLIP-Seq data. Nucleic Acids Res 42 (Database Issue): D92-D97, 2014

32. Barnes $C$ and Kanhere A: Identification of RNA-protein interactions through in vitro RNA pull-down assays. Methods Mol Biol 1480: 99-113, 2016.

33. Wang M and Pestov DG: Quantitative northern blot analysis of mammalian rRNA processing. Methods Mol Biol 1455: 147-157, 2016.

34. Ji ML, Lu J, Shi PL, Zhang XJ, Wang SZ, Chang Q, Chen H and Wang C: Dysregulated miR-98 contributes to extracellular matrix degradation by targeting IL-6/STAT3 signaling pathway in human intervertebral disc degeneration. J Bone Miner Res 31: 900-909, 2016.

35. Wang HQ, Yu XD, Liu ZH, Cheng X, Samartzis D, Jia LT, Wu SX, Huang J, Chen J and Luo ZJ: Deregulated miR-155 promotes Fas-mediated apoptosis in human intervertebral disc degeneration by targeting FADD and caspase-3. J Pathol 225 : $232-242,2011$

36. Lu ZJ, Lu LG, Tao KZ, Chen DF, Xia Q, Weng JJ, Zhu F, Wang XP and Zheng P: MicroRNA-185 suppresses growth and invasion of colon cancer cells through inhibition of the hypoxiainducible factor- $2 \alpha$ pathway in vitro and in vivo. Mol Med Rep 10: 2401-2408, 2014

37. Yin C, Zhang G, Sun R, Pan X, Wang X, Li H and Sun Y: MiR1855p inhibits Factin polymerization and reverses epithelial mesenchymal transition of human breast cancer cells by modulating RAGE. Mol Med Rep 18: 2621-2630, 2018.

38. Zhao CQ, Jiang LS and Dai LY: Programmed cell death in intervertebral disc degeneration. Apoptosis 11: 2079-2088, 2006.
39. Kozaci LD, Guner A, Oktay G and Guner G: Alterations in biochemical components of extracellular matrix in intervertebral disc herniation: Role of MMP-2 and TIMP-2 in type II collagen loss. Cell Biochem Funct 24: 431-436, 2006.

40. Matsui Y, Maeda M, Nakagami W and Iwata $H$ : The involvement of matrix metalloproteinases and inflammation in lumbar disc herniation. Spine (Phila Pa 1976) 23: 863-868, 1998.

41. Crean JK, Roberts S, Jaffray DC, Eisenstein SM and Duance VC: Matrix metalloproteinases in the human intervertebral disc: Role in disc degeneration and scoliosis. Spine (Phila Pa 1976) 22: 2877-2884, 1997.

42. Kepler CK, Ponnappan RK, Tannoury CA, Risbud MV and Anderson DG: The molecular basis of intervertebral disc degeneration. Spine J 13: 318-330, 2013.

43. Tran CM, Smith HE, Symes A, Rittié L, Perbal B, Shapiro IM and Risbud MV: Transforming growth factor beta controls CCN3 expression in nucleus pulposus cells of the intervertebral disc. Arthritis Rheum 63: 3022-3031, 2011.

44. Sivan SS, Wachtel E and Roughley P: Structure, function, aging and turnover of aggrecan in the intervertebral disc. Biochim Biophys Acta 1840: 3181-3189, 2014.

45. Perera RS, Dissanayake PH, Senarath U, Wijayaratne LS, Karunanayake AL and Dissanayake VH: Single nucleotide variants of candidate genes in aggrecan metabolic pathway are associated with lumbar disc degeneration and modic changes. PLoS One 12: e0169835, 2017.

46. Rutges JP, Kummer JA, Oner FC, Verbout AJ, Castelein RJ, Roestenburg HJ, Dhert WJ and Creemers LB: Increased MMP-2 activity during intervertebral disc degeneration is correlated to MMP-14 levels. J Pathol 214: 523-530, 2008.

47. Vo NV, Hartman RA, Yurube T, Jacobs LJ, Sowa GA and Kang JD: Expression and regulation of metalloproteinases and their inhibitors in intervertebral disc aging and degeneration. Spine J 13: 331-341, 2013

48. Rutges JP, Nikkels PG, Oner FC, Ottink KD, Verbout AJ, Castelein RJ, Creemers LB and Dhert WJ: The presence of extracellular matrix degrading metalloproteinases during fetal development of the intervertebral disc. Eur Spine J 19: 1340-1346, 2010.

49. Boxler S, Djonov V, Kessler TM, Hlushchuk R, Bachmann LM, Held U, Markwalder R and Thalmann GN: Matrix metalloproteinases and angiogenic factors: Predictors of survival after radical prostatectomy for clinically organ-confined prostate cancer? Am J Pathol 177: 2216-2224, 2010.

50. Song J, Wu C, Korpos E, Zhang X, Agrawal SM, Wang Y, Faber C, Schäfers M, Körner H, Opdenakker G, et al: Focal MMP-2 and MMP-9 activity at the blood-brain barrier promotes chemokine-induced leukocyte migration. Cell Rep 10: 1040-1054, 2015

51. Phillips KL, Cullen K, Chiverton N, Michael AL, Cole AA, Breakwell LM, Haddock G, Bunning RA, Cross AK and Le Maitre CL: Potential roles of cytokines and chemokines in human intervertebral disc degeneration: Interleukin-1 is a master regulator of catabolic processes. Osteoarthritis Cartilage 23: $1165-1177,2015$

52. Wang J, Tian Y, Phillips KL, Chiverton N, Haddock G, Bunning RA, Cross AK, Shapiro IM, Le Maitre CL and Risbud MV: Tumor necrosis factor $\alpha$ - and interleukin-1 $\beta$ dependent induction of CCL3 expression by nucleus pulposus cells promotes macrophage migration through CCR1. Arthritis Rheum 65: 832-842, 2013.

53. Zhang $\mathrm{H}$, Zhang M, Meng L, Guo M, Piao M, Huang Z and Yu H: Investigation of key miRNAs and their target genes involved in cell apoptosis during intervertebral disc degeneration development using bioinformatics methods. J Neurosurg Sci, Feb 4, 2020 (Epub ahead of print).

54. Riesenburger RI, Safain MG, Ogbuji R, Hayes J and Hwang SW: A novel classification system of lumbar disc degeneration. J Clin Neurosci 22: 346-351, 2015

This work is licensed under a Creative Commons Attribution-NonCommercial-NoDerivatives 4.0 International (CC BY-NC-ND 4.0) License. 